\title{
PENERAPAN KONSEP FLEXIBLE DAN GREEN ARCHITECTURE PADA RUMAH TYPICAL DI LAMPUNG
}

\author{
Ai Siti Munawaroh1, Rachmat Ade Gunawan², Satrio Agung Perwira ${ }^{3}$ \\ ${ }^{1,2,3}$ Arsitektur, Fakultas Teknik, Universitas Bandar Lampung, Jl. ZA. Pagar Alam No.21 \\ Bandar Lampung, 35142 \\ *aisiti.arch@ubl.ac.id
}

\begin{abstract}
ABSTRAK. Rumah merupakan salah satu kebutuhan pokok manusia. Kebutuhan manusia di dalam rumah berbeda-beda. Keberadaan perumahan yang menyediakan rumah typical menjadi salah satu solusi dalam pemenuhan kebutuhan rumah bagi masyarakat.Namun rumah typical masih menimbulkan permasalahan, yaitu adanya aktivitas dan kebutuhan ruang dari penghuni yang tidak bisa terakomodir. Disisi lain permasalahan lingkungan akibat dari aktivitas manusia di dalam rumah menimbulkan dampak negatif bagi lingkungan. Lampung merupakan salah satu daerah yang memiliki arsitektur yang khas. Tetapi rumah typical yang dikembangkan oleh para developer perumahan belum ada yang menonjolkan arsitektur khas Lampung tersebut.
\end{abstract}

Penelitian ini dilakukan untuk merancang rumah yang dapat memenuhi kebutuhan masing-masing penghuni rumah dengan luas bangunan yang sama. Selain itu, rumah yang dirancang tidak menimbulkan dampak negatif bagi lingkungan dan mencirikan arsitektur Lampung.Metode penelitian yang digunakan adalah kualitatif. Metode kualitatif dilakukan melalui studi literatur dan perancangan. Studi literatur dilakukan melalui kajian dari berbagai sumber yaitu buku, jurnal dan internet. Perancangan dilakukan melalui: penerapan konsep flexible house dan konsep green architecture serta transformasi bentuk hasil kebudayaan Lampung.Hasil penelitian adalah desain rumah typical di Lampung dengan konsep green flexible house.

Kata kunci: green architecture, flexible house, rumah lampung

ABSTRACT. A house is one of the basic human needs. Human needs of house for each people is different. The existence of housing that provides typical house become one of the significant solutions to fulfill the needs of house for community. However, typical house is still causing problems for the occupants, because this typical house cannot accommodate all the occupants' activities within it. I tbecause, typical house is a minimum standard for living which is different for each people. On the other hand, environmental problems which is occurred by human activities within a house could raise negative impact for the environment. Lampung has been regarded as one of an area which has a distinctive character of architecture. But the typical house that is developed by the developer, have not described and represented the character of Lampung'sarchitecture.

This study has been conducted to design a house that would fulfill the needs of occupants of the house which has the same area space of the house. Additionally, the house has been designed to eliminate negative impact for the environment and would have a significant character for Lampung'sarchitecture. This research has used a qualitative method, which has been done by using literature study and design process. Literature study has been conducted by reviewing some relevant books, journal sand various sources from worldwide web. And finally, design process has been conducted through: the application of flexible house and green architecture concept and the transformation of the Lampung'sculture. As a final result, this research will provide a design of typicalhouse in Lampung with green flexible house concept.

Keywords: green architecture; flexible house; Lampung house

\section{PENDAHULUAN}

Rumah merupakan kebutuhan primer manusia. Rumah juga mewadahi berbagai aktivitas penghuni rumah yang ada di dalamnya. Menurut Soetalaksana [1] rumah merupakan salah satu bagian penting dalam kehidupan masyarakat, oleh sebab itu pemenuhannya akan selalu diusahakan dalam tingkat kehidupan setiap orang, dengan memperhatikan selera dan kemampuan keuangan yang ada. Keberadaan perumahan yang menyediakan rumah typical menjadi salah satu solusi dalam pemenuhan kebutuhan rumah bagi masyarakat. Namun, rumah typical masih menimbulkan permasalahan, yaitu adanya aktivitas dan kebutuhan ruang dari 
masing-masing penghuni yang tidak bisa terakomodir. Disisi lain permasalahan lingkungan akibat dari aktivitas manusia di dalam rumah menimbulkan dampak negatif bagi lingkungan. Dampak lingkungan yang sering ditemui di Lampung diantaranya pencemaran air sungai dan air tanah, kekurangan air bersih akibat terlalu banyak sumur artesis serta limpasan air hujan yang menggenang di jalan. Lampung sebagai salah satu daerah yang memiliki arsitektur yang khas. Tetapi rumah typical yang dikembangkan oleh para developer perumahan belum ada yang menonjolkan arsitektur khas Lampung. Oleh karenanya diperlukan adanya penelitian mengenai rumah typical yang mengakomodir penghuni rumah dan tidak menimbulkan dampak negatif bagi lingkungan dengan menonjolkan arsitektur khas Lampung.

Rumusan permasalahan penelitian ini adalah: 1) Bagaimana desain rumah typical yang dapat disesuaikan dengan kebutuhan masing-masing penghuni; 2) Bagaimana desain rumah yang tidak menimbulkan dampak negatif pada lingkungan; 3) Bagaimana desain rumah yang mencirikan kebudayaan Lampung. Sedangkan tujuan dari penelitian ini adalah: 1) Mendesain rumah typical yang dapat disesuaikan dengan kebutuhan masing-masing penghuni; 2) Mendesain rumah yang tidak menimbulkan dampak negatif pada lingkungan; 3) Mendesain rumah yang mencirikan mencirikan kebudayaan Lampung.

\section{METODE PENELITIAN}

Lingkup Studi Penelitian ini dibatasi pada rumah tinggal dua lantai dengan menggunakan konsep flexible dan green. Metode penelitian menggunakan studi literatur dilakukan melalui berbagai sumber yaitu buku, jurnal dan internet. Sedangkan metode penelitian berikutnya dengan menggunakan metode perancangan dilakukan melalui: 1) Penerapan konsep flexible house; 2) Penerapan konsep green architecture; 3) Transformasi bentuk hasil kebudayaan Lampung.

\section{Arsitektur Tradisional Lampung}

Tipologi rumah tradisional merupakan rumah yang lahir dari budaya dan sistem nilai masyarakat setempat. Metode perancangan ini telah teruji oleh waktu dan tempat, karenanya kemampuan adaptasi terhadap lingkungan dan kondisi bangsa ini tentu juga telah teruji. Satu hal yang penting dari pendekatan ini adalah ia mencerminkan budaya dan identitas dari bangsa kita karenanya dapat menjadi suatu bentuk kebanggan kita.

Memperjelas apa yang telah disampaikan sebelumnya bahwa untuk tipologi sebuah rumah kita memiliki identitas dan produk tersendiri. Pada rumah tradisional kita mendapati bahwa bahan yang digunakan merupakan bahan yang mudah didapati di lokasi pembangunan sehingga dapat mengurangi biaya konstruksi. Atap yang digunakan pun merupakan bumbung meru yang sesuai dengan iklim setempat dan merupakan suatu bentuk adaptasi terhadap sistem nilai serta budaya setempat.

\section{Morfologi Arsitektur}

Sejarah terbentuknya arsitektur tradisional Lampung secara umum dapat dibagi dalam dua faktor yaitu, faktor eksternal dan faktor internal. Faktor eksternal adalah masuknya kebudayaan dari luar Indonesia yang menyatu dengan kebudayaan lokal. Perkiraan sejarah budaya Lampung dimulai dari zaman Hinduisme (pemulaan abad 16), yaitu zaman masuknya ajaran - ajaran atau sistem kebudayaan yang berasal dari daratan india termasuk budhisme yang unsurnya terdapat pada adat budaya di daerah lampung. Akan tetapi pengaruh Hinduisme ini skalanya sangat sedikit

Sedangkan sebagai faktor internal, Zaman Malayo Polinesia (sekitar abad 6 - 17), merupakan puncak perubahan budaya yang sangat besar bagi kepercayaan dan adat istiadat orang lampung. Pengaruh Islam mulamula dari daerah Aceh, dibuktikan dengan adanya pengaruh motif ukiran aceh pada beberapa unsur bangunan arsitektur di beberapa daerah Lampung, terutama pada daerah Lampung bagian Barat.

Sedangkan pengaruh arsitektur dari daerah lain adalah pengaruh arsitektur dari daerah Palembang terutama Meranjat yang dapat dilihat dari jenis motif ukiran dan teknik konstruksinya. Motif ukiran kapal dan motif pucuk rebung adalah salah dua yang menjadi ciri khas dari arstitektur Lampung. 


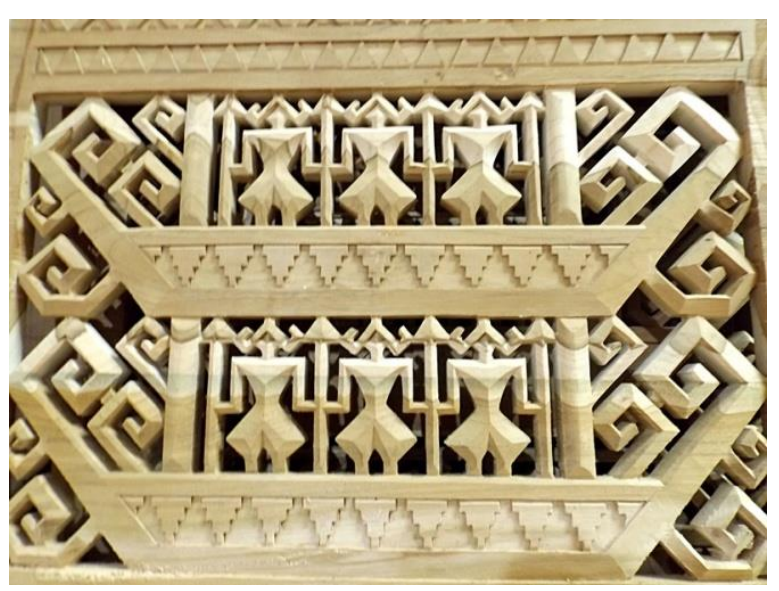

Gambar 1. Ukiran Motif Kapal (Sumber: [2])

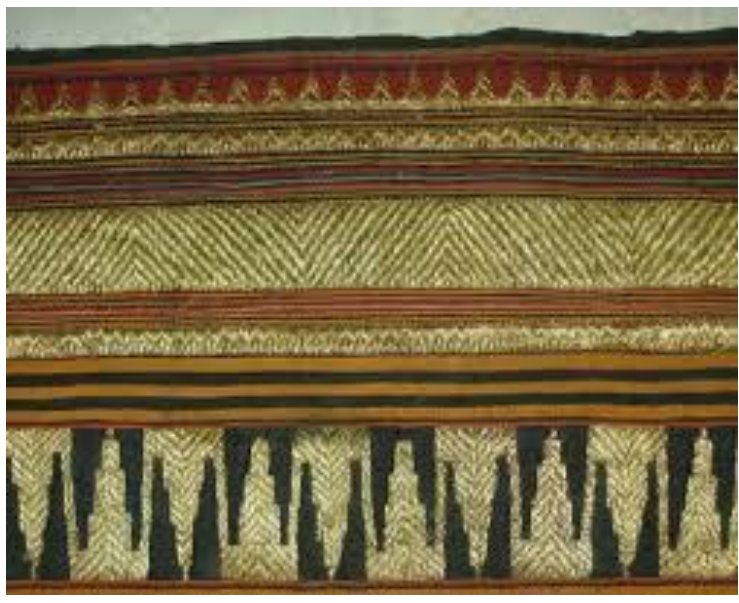

Gambar 2. Motif Kain Tapis Pucuk Rebung (Sumber: [3])

Dari beberapa unsur kepercayaan lama terlihat adanya beberapa pengertian kosmologis yang melambangkan adanya suatu unsur dualisme yang membagi alam semesta. Dua hal itu saling bertentangan, misalkan dunia atas dan dunia bawah. Secara filosofis konsepsi adat orang lampung, sistem pertentangan dari dua unsur itu dapat dinetralkan melalui perkawinan dua unsur yang saling bertentangan sehingga dapat diciptakan keseimbangan cosmos yang termanifestasikan dalam kehidupan dunia tengah.

\section{Tinjauan Arsitektur Tradisional Lampung Barat}

Menganalisis artefak budaya dan arsitektur desa Kenali, tergambarlah cerminan konsepsi arsitekturnya dalam bentuk perlambangperlambang yang dapat dilihat pada unsur arsitektur rumahnya yang dapat diaplikasikan dalam perencanaan sebagai identitas dari bangunan.
Adapun bentuk dari ornamen perlambang tersebut, adalah : 1) Aghi adalah: Tiang bagian bawah, menggunakan menggunakan kayu besar berbentuk bulat; 2) Culu langi adalah: kayu utama yang menyatukan struktur rangka kap pada bagian atasnya sebagai lambang roh dan kekuatan sebuah rumah; 3) Paguk adalah: Hiasan pada sudut pertemuan balok - balok utama penyangga lantai yang berupa ukiran ukiran berbentuk tanduk dengan bentuk melengkung ke atas seperti haluan perahu; 4) Atap : Perlambang dunia atas dengan intinya ruang panggar, digambarkan dengan jenis berung, gambar nenek moyang yang berupa roh, pucuk - pucuk pohon hayat serta disimbolkan dengan warna merah.

Ditinjau dari jenis penggunaan bahan untuk bangunan arsitekturnya secara keseluruhan menggunakan jenis bahan organis yang ringan, seperti struktur rangka kayu untuk bagian bawah sedangkan bagian atas dikombinasi antara kayu dan bambu serta menggunakan penutup atap bahan ijuk.

Secara umum kemampuan bahan organis berserat untuk menahan tarik rata - rata mencapai tiga kali kemampuan kuat tekan kearah serat. Karena itu untuk penggunaan bahan organis seperti kayu sangat ideal untuk digunakan pada konstruksi yang menggunakan prinsip struktur beban tarik.

Bentuk dasar konstruksi bangunan tradisional kenali adalah bangunan segi empat. Pengaturan massa bangunan juga sesuai dengan prinsip kontruksi tahan gempa, dimana untuk pemindahan beban massa bangunan dipindahkan ketiang - tiang bulat yang besar sesuai dengan ekspresi besarnya beban yang diterima dari massa bangunan bagian atas.

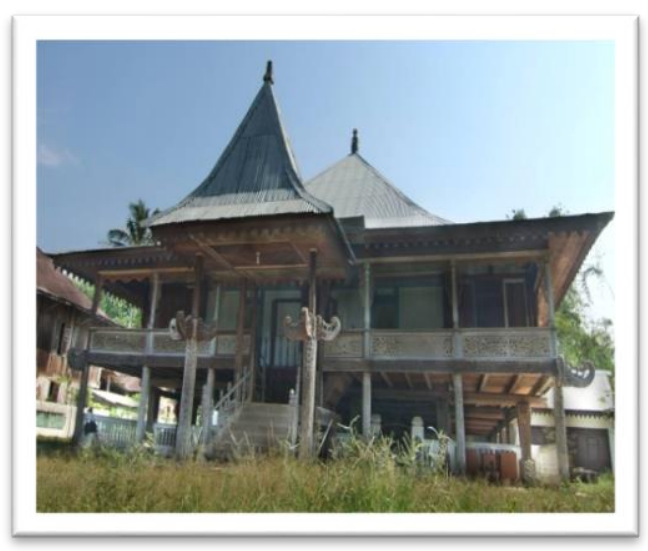

Gambar 3. Bentuk Rumah Tradisional Lampung Barat

(Sumber: [4]) 
Bentuk hiasan lain yang ada pada rumah masyarakat kenali adalah bentuk pintu jendela pada lebing tengah, yang dinamakan singkapan kebik, lobang jendela itu berbentuk lubang untuk mengintip dipelataran publik dimuka rumah.

Analisis konsepsi adat budaya masyarakat Lampung khususnya di desa Kenali yang banyak termanifestasikan dalam pemikiran filosofi yang digambarkan dalam kain adatnya. Terlihat adanya pembagian kosmos dalam kombinasi klasifikasi dua ke dalam tiga tingkatan cosmologis. Dan dari sebagian besar motif pada kain juga secara konsepsi dan kosmologis ada beberapa kesamaan dengan konsepsi budaya perahu yang terekspresi pada bangunan arsitektur perlambang perahu. Untuk dapat menarik kesimpulan terhadap pernyataan diatas, maka sebagai dasarnya akan dibandingankan bentuk - bentuk konsep fisik arsitektur tradisional yang ada di Kenali dengan bangunan arsitektur yang secara teroritis dianggap merupakan arsitektur perlambang perahu yang ada di daerah Indonesia dengan melihat kemiripan bentuk serta fungsi simbolnya. Karena untuk menyampaikan esensi sesuatu yang disimbolkan, dapat diabstraksikan konsep gagasan tentang sesuatu (idea).

\section{Flexible House}

Flexible house adalah rumah yang dapat mengadaptasi perubahan dan kebutuhan penghuninya. Flexible house sangat relevan; penting; rumah masa depan yang berlandaskan pada aspek ekonomi, sosial dan lingkungan yang berkelanjutan.

Flexible house lebih jauh memberikan pilhan yang berbeda pada layout ruang yang dibutuhkan oleh penghuni sebaik mungkin meskipun hanya memiliki satu rumah. Flexible house juga dapat disesuaikan dengan perkembangan teknologi, perubahan demografi atau bahkan perubahan fungsi bangunan dari rumah tinggal ke fungsi yang lain.

Jadi flexible house adalah kategori rumah yang lebih luas dibanding rumah yang dapat diadaptasi. Ini merupakan konsep umum yang dapat digunakan untuk rumah yang dapat mengadaptasi kebutuhan fisik penghuni, khususnya saat mereka tumbuh menua dan kehilangan kemampuan mobilitas [5]

\section{Green Architecture}

Pengertian green building adalah praktek pembangunan dengan cara membuat dan menggunakan sumber daya yang lebih sehat dan efisien, meminimalkan dampak negatif pada lingkungan alam pada tahap konstruksi renovasi, operasi, pemeliharaan dan pembongkaran [6].

Konsep green building ada sebelas. Pertama merancang bangunan secara berkelanjutan yaitu bangunan dirancang untuk tujuan saat ini dan masa mendatang [7]. Kedua, memilih dan mengolah tapak yang aman [8] dan responsif terhadap isu-isu global [7]. Ketiga, meminimalkan konsumsi sumber daya alam melalui pemanfaatan yang lebih efisien sumber daya alam tidak terbarukan, tanah, air, dan bahan bangunan [8][9] Ke empat menggunakan bahan dan sumber daya lokal [7][10]. Kelima, menghemat energi tidak terbarukan dan bahan langka [10][11]. Keenam menggunakan energi terbarukan [7][8][11]. Ketujuh, mengurangi paparan bahan berbahaya yang dapat mencemari lingkungan dan membahayakan manusia [9][10][11]. Kedelapan, meminimalkan emisi yang berdampak negatif terhadap lingkungan dalam ruangan dan atmosfer planet, khususnya yang berkaitan dengan kualitas udara dalam ruangan, gas rumah kaca, pemanasan global dan partikulat [9] serta menggunakan teknologi bersih [10]. Kesembilan, memaksimalkan kualitas lingkungan dalam ruangan, termasuk kualitas udara, rezim termal, pencahayaan, akustik/ kebisingan dan aspek visual untuk memberikan persepsi kenyamanan manusia secara fisik dan psikis [9][11]. Kesepuluh, meminimalkan pembuangan limbah padat dan limbah cair, termasuk limbah pembongkaran, rumah tangga, dan air hujan serta membangun infrastruktur terkait yang diperlukan untuk mengakomodasi pembuangan agar limbah yang dibuang tidak menimbulkan dampak negatif [7][8]. Kesebelas, mendukung pejalan kaki, sepeda, angkutan massal dan alternatif lain untuk kendaraan berbahan bakar fosil [11]. 
HASIL PENELITIAN DAN PEMBAHASAN

\section{Konsep Desain Kapal}

\section{Konsep Fasade}
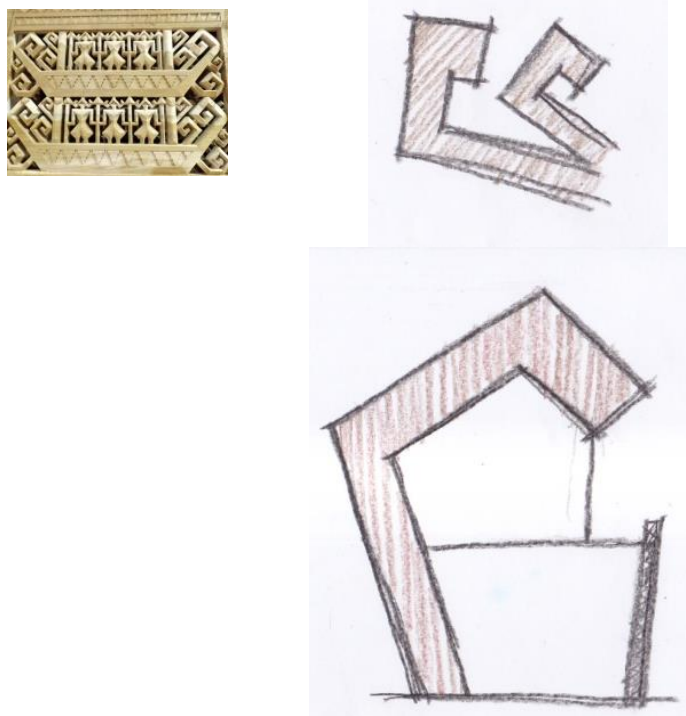

Gambar 4. Konsep Fasade 1

(Sumber: Penulis, 2016)

Kapal merupakan salah satu simbol kebudayaan Lampung. Dimana Lampung merupakan salah satu daerah yang dikelilingi laut. Kapal merupakan simbol untuk mencapai derajat yang lebih tinggi. Tranformasi kapal diaplikasikan ke dalam fasade bangunan yaitu tiang yang menerus sampai ke atap. Selain itu tangga juga merupaka tranformasi dari bentuk kapal.

\section{Motif pucuk rebung pada kain tapis}

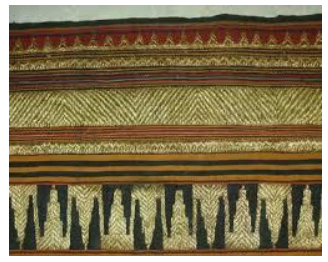

\section{Konsep Fasade}
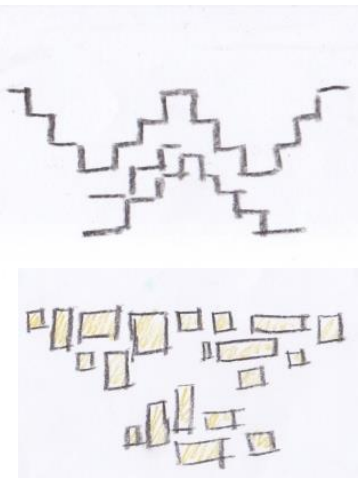

Gambar 5. Konsep Fasade 2

(Sumber: Penulis, 2016)

Konsep Fasade bagian kiri bangunan yaitu tranformasi dari bentuk pucuk rebung. Pucuk rebung merupakan salah satu motif dari kain tapis Lampung. Pucuk rebung filosofi utamanya yaitu melambangkan kemakmuran.

\section{Bentuk Rumah Tradisional Lampung \\ Konsep Gubahan Massa}
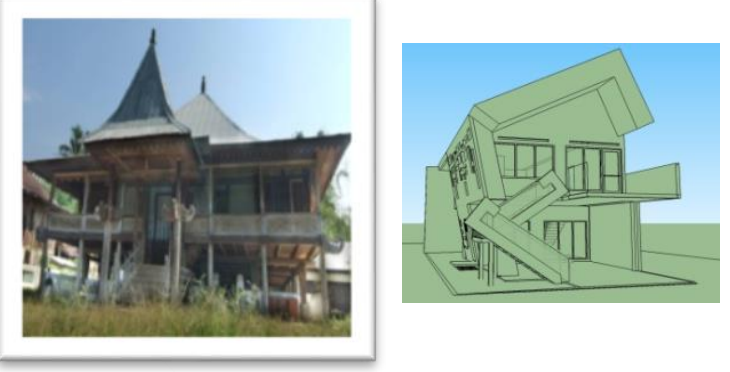

Gambar 6. Konsep Gubahan Massa

(Sumber: Penulis, 2016)

Ruh masyarakat adat Lampung itu bertumpu pada empat hal yaitu Keberanian (Bani), kemapanan (Pawar), IImu Pengetahuan (Nalom), dan kebersamaan (Kemuarian). Empat hal tersebut adalah empat pilar bagi Sai Batin bersama jamma/jelmanya dalam menegakkan kehangguman Gedung Dalom / Lamban Gedung, agar degup jantung itu terus dan senantiasa berirama hingga menjemput takdir Tuhan dihari yang paling kemudian, makna nilai tersebutlah yang sering diwujudkan dalam simbol simbol empat pada ornamen ataupun tiang tiang rumah adat Lampung.

Secara berurutan memasuki Lamban Gedung dapat dijumpai beberapa bagian seperti Jan atau tangga masuk, selanjutnya menaiki tangga dimuka rumah melalui beranda kecil 
disebut "usud" untuk menuju keberanda yang sebenarnya atau disebut "Lepau" yaitu ruang terbuka pada bagian atas depan rumah. Lalu setelah memasuki Pintu Utama maka dijumpai bagian dalam Lamban Gedung, terdapat satu ruang besar sebagai tempat Sai Batin beristirahat disebut Bilik Kebik. Tak ada yang masuk ke ruang itu kecuali Sai Batin dan Permaisuri atau kerabat yang diizinkan oleh Sai Batin. Di dalam ruangan itu, terdapat pula sejumlah senjata pusaka yang hanya Sai Batin atau Sultan yang berani memindah atau membukanya. Di depan pintu Bilik Kebik terdapat pelaminan atau singgasana yang disebut margasana. Alas duduk Sai Batin terdiri atas kasur berlapis-lapis, taber atau kain hiasan dinding, dan langit-langit yang terbuat dari kain beludru warna warni dan manikmanik yang disebut Leluhor Kejuntai. Dari dalam singgasana itulah Sai Batin memimpin sidang (hippun paksi) menghadap seluruh raja suku/ jukkuan duduk bersila. Hanya Sai Batin dan Raja Jukkuan yang boleh duduk di tempat ini pada saat hippun paksi.

Dari uraian diatas didapat konsep gubahan massa dari rumah tradisional Lampung yaitu rumah panggung yang diintrepretasikan menjadi rumah dua lantai yang ditumpu oleh beberapa tiang.

\section{Konsep Ruang}

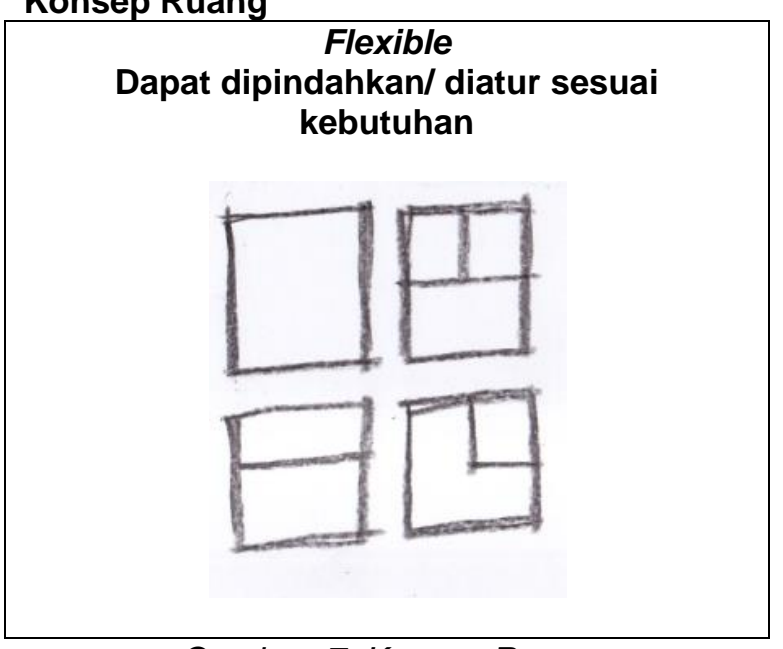

Gambar 7. Konsep Ruang

(Sumber: Penulis, 2016)

Rumah ini didesain untuk memenuhi kebutuhan setiap orang. Dengan luas rumah $180 \mathrm{~m} 2$ dan luas tanah yaitu lebar $10 \mathrm{~m}$ dan panjang $20 \mathrm{~m}$ (luas $200 \mathrm{~m} 2$ ). Dinding dalam rumah (partisi) dibuat dengan menggunakan roda pada bagian bawah sehingga bisa digeser sesuai kebutuhan pengguna ruang. Dinding permanen hanya pada bagian luar dan kamar mandi. Pintu juga dapat dipindah sesuai kebutuhan. Rumah ini disebut green flexible house karena bisa digeser-geser dan luas masing-masing ruang bisa disesuaikan dengan kebutuhan masing-masing penghuni rumah.

\section{Konsep Utilitas}

\section{Air Bersih}

Sumber bersih yaitu dari Perusahaan Daerah Air Minum (PDAM) atau sumur artesis lingkungan perumahan. Alasan tidak membuat sumur sendiri di kavling, karena terlalu banyak sumur akan mengakibatkan kerusakan pada tanah.

Dari PDAM/ sumur artesis lingkungan perumahan, ditampung di ground tank (tanki bawah). Hal ini bertujuan agar ketersediaan air di dalam rumah dapat terjamin. Dari ground tank di pompa ke tanki air yang ada di bagian atas lantai dua. Tujuannya agar air dapat dialirkan ke kamar mandi, dapur dan kran tidak menggunakan pompa dan menghemat listrik. Air dialirkan dengan sistem gravitasi (air mengalir dari tempat yang tinggi ke tempat yang lebih rendah). Pipa yang digunakan dari tabung air yaitu PVC AW diameter 1". Sedangkan ke masing-masing kamar mandi dan dapur menggunakan diameter 3/4" dan ke kran diameter $1 / 2$ ". Penggunaan jenis pipa dari tabung ke kran dimaksudkan agar debit air yang keluar ke masing-masing kran bisa stabil.

Pada pertemuan/sambungan antara pipa digunakan stop kran. Hal ini dimaksudkan agar apabila ada perbaikan di salah satu kamar mandi, dapat distop dulu airnya. Sementara kamar mandi/ kran lain dapat terus berfungsi. Selain itu, adanya instalasi yang memudahkan dalam proses perawatan adalah salah satu kriteria green utility. 


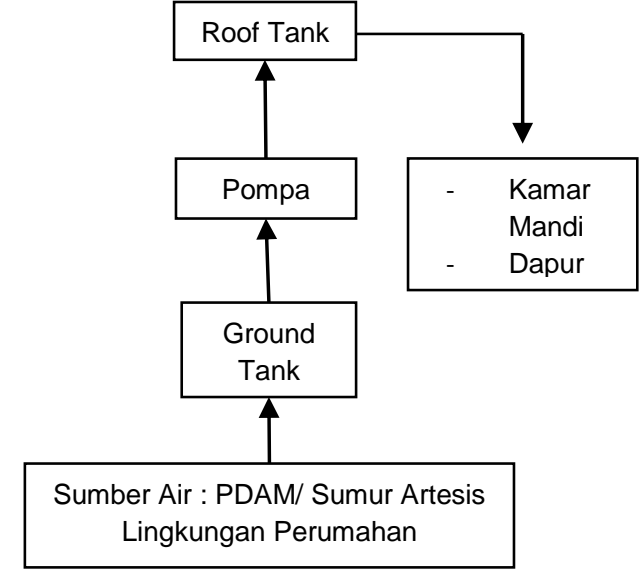

Gambar 8. Skema Air Bersih

(Sumber: Penulis, 2016)

\section{Air Hujan}

Air hujan dipanen dan ditampung di dalam ground tank. Kapasistas ground tank terbatas, untuk mengantisipasinya di buat sumur resapan sebagai penampung.

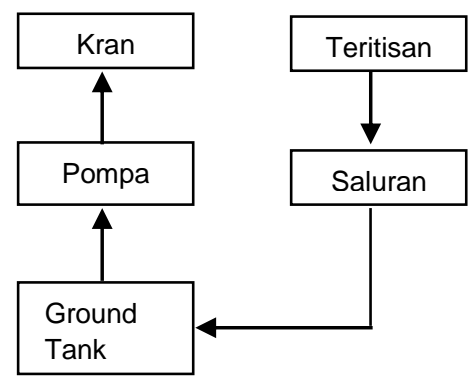

Gambar 9. Skema Air Hujan

(Sumber: Penulis, 2016)

\section{Air Bekas}

Air bekas dari mandi dan cuci dipisahkan dari air limbah dan dialirkan ke dalam ground tank yang selanjutnya dialirkan ke sumur resapan.

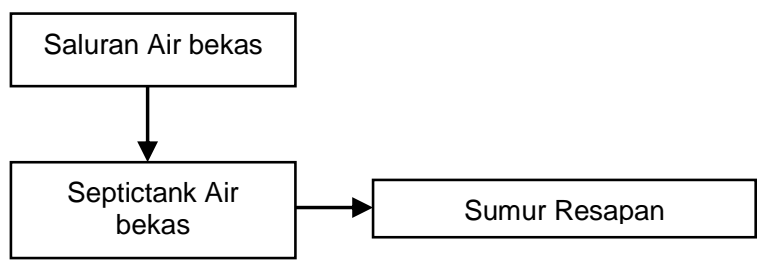

Gambar 10. Skema Air Bekas (Sumber: Penulis, 2016)

\section{Air Limbah}

Air limbah dari closet di salurkan ke septictank. Di dalam septictank diolah secara alami melalui desain septictank kemudian dialirkan ke sumur resapan.

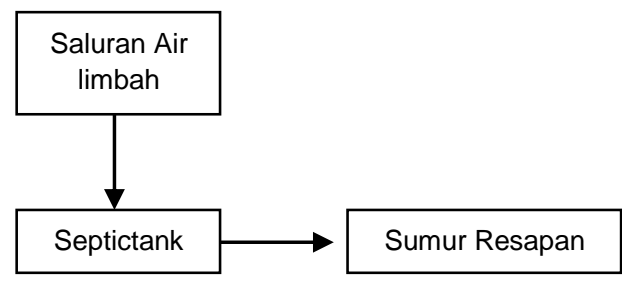

Gambar 11. Skema Air Limbah (Sumber: Penulis, 2016)

\section{Rekayasa Material}

\section{Beton Struktur}

Beton struktur (pondasi, kolom, ringbalk, plat lantai dan tangga) menggunakan beton K-225 (Ready-Mix Concrete/RMC).

\section{Beton Arsitektur}

Beton arsitektur (frame kusen dan meja beton) menggunakan beton K-175 site mix dengan memakai Ordinary Portland Cement (OPC) tipe II untuk memberikan perlindungan tambahan terhadap kandungan sulfat di air dan tih tanah.

\section{Eksterior}

Semen putih digunakan untuk dekorasi eksterior dan interior gedung.

\section{Nat dan Aci}

Nat dan acian menggunakan Acian Putih TR30 sangat sesuai untuk pekerjaan acian dan nat. Komposisi Acian Putih TR30 antara lain Semen Putih kapur (Kalsium Karbonat) dan bahan aditif khusus lainnya. Keuntungan menggunakan Acian Putih TR30 adalah menghasilkan permukaan acian yang lebih halus, mengurangi retak dan terkelupasnya permukaan karena mempunyai sifat plastis dengan daya rekat tinggi, cepat dan mudah dalam pengerjaan, hemat dalam pemakaian bahan serta dapat dipergunakan pada permukaan beton dengan menambahkan bonding agent.

\section{Fasade}

Material bambu digunakan pada fasade bagian kiri bangunan. Bambu merupakan salah satu sumber daya yang banyak terdapat di seluruh Indonesia khususnya Lampung. 


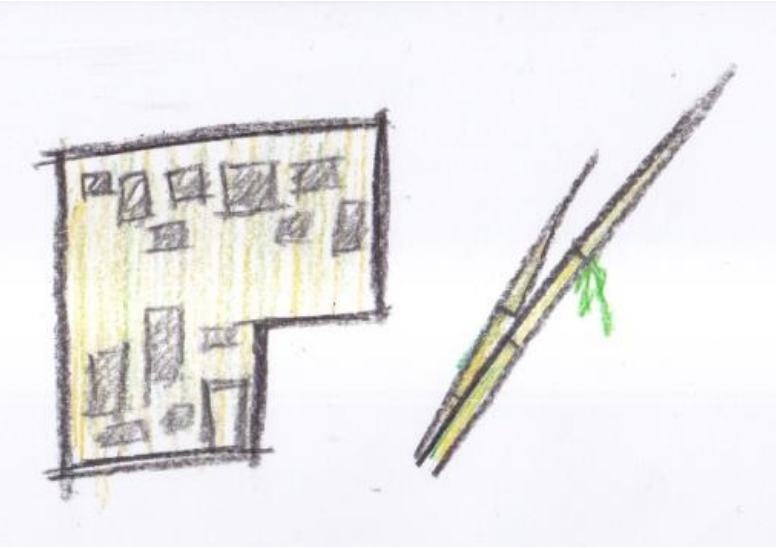

Gambar 12. Material Bambu

(Sumber: Penulis, 2016)

\section{Partisi}

Konstruksi dinding partisi menggunakan baja dan baja ringan. sedangkan penutup dinding menggunakan gypsum lapis karpet. Alasan menggunakan gypsum karena bahan ini lebih umum digunakan sebagai pelapis partisi. Sedangkan penambahan lapisan karpet, agar partisi tersebut dapat meredam suara di masing-masing ruangan.

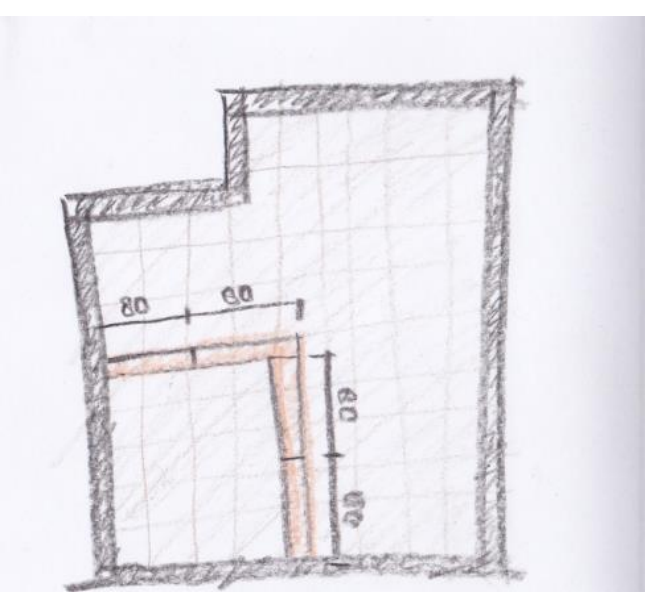

Gambar 13. Partisi

(Sumber: Penulis, 2016)

Modular partisi yaitu lebar $80 \mathrm{~cm}$ dan tinggi $320 \mathrm{~cm} .80 \mathrm{~cm}$ dipilih karena rata-rata lebar pintu+kusen $80 \mathrm{~cm}$. Sehingga memudahkan dalam memidahkan pintu. Sedangkan $320 \mathrm{~cm}$ adalah tinggi plafond.

Modul 1 dengan modul lainnya disatukan dengan cara knockdown. Sistem ini juga dilengkapi dengan sistem pengunci yang kuat tapi lagi-lagi fleksible. Bisa dibongkar dan dipasang dengan mudah.
Roda sengaja disembunyikan agar partisi benar-benar menutup ruang satu dengan ruang lainnya. Roda juga sistemnya dapat dikunci sehingga apabila ada barang/ orang yang menyentuh partisi, partisi tersebut tidak bergeser.

\section{Konsep Vegetasi}

Dinding pagar bagian samping dan depan dimanfaatkan untuk vertical garden. Media vertical garden menggunakan botol bekas. Hal ini bertujuan untuk memanfaatkan lahan terbatas sekaligus menggunakan kembali limbah plastik yang biasanya mencemari lingkungan. Selain itu rumah akan segar karena adanya oksigen yang dihasilkan oleh vegetasi.
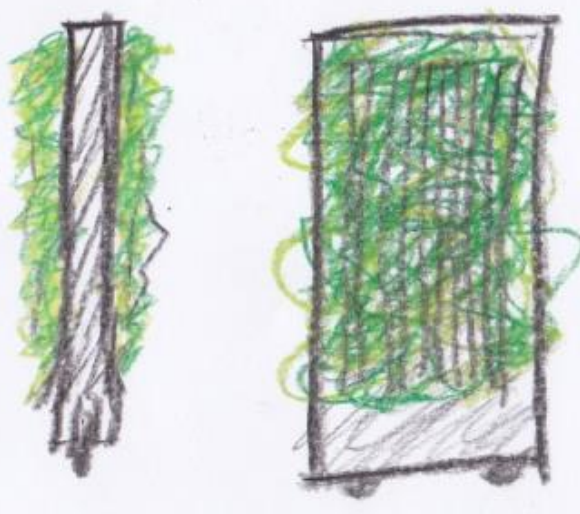

Gambar 14. Konsep Vegetasi (Sumber: Penulis, 2016)

\section{Keberlanjutan Manfaat}

Lampung Green Flexible House dapat dibangun sebagai salah satu solusi terhadap permasalahan manusia dan lingkungan. Permasalahan manusia yaitu keinginan penghuni rumah dapat terakomodir dalam hal penataan ruang. Permasalahan lingkungan teratasi dengan tidak dibuatnya sumur artesis di kavling tanah tersebut. Air bekas dan air limbahpun diolah sehingga tidak mencemari tanah. Sedangkan air hujan dimanfaatkan kembali untuk keperluan mencuci dan menyiram tanaman.

Bila dibangun secara massal di Lampung dapat memberikan dampak positif bagi pencari rumah ramah lingkungan. Konsep dari Lampung Green Flexible House ini juga dapat diaplikasikan di daerah Indonesia lainnya dengan mengkodisikan dengan kearifan lokal daerah tersebut. 


\section{Gambar dan Deskripsi Desain}

\section{Gambar Tiga Dimensi}

Berikut adalah gambar tampak depan 1 dan depan 2 seperti terlihat dalam Gambar 15 dan Gambar 16.

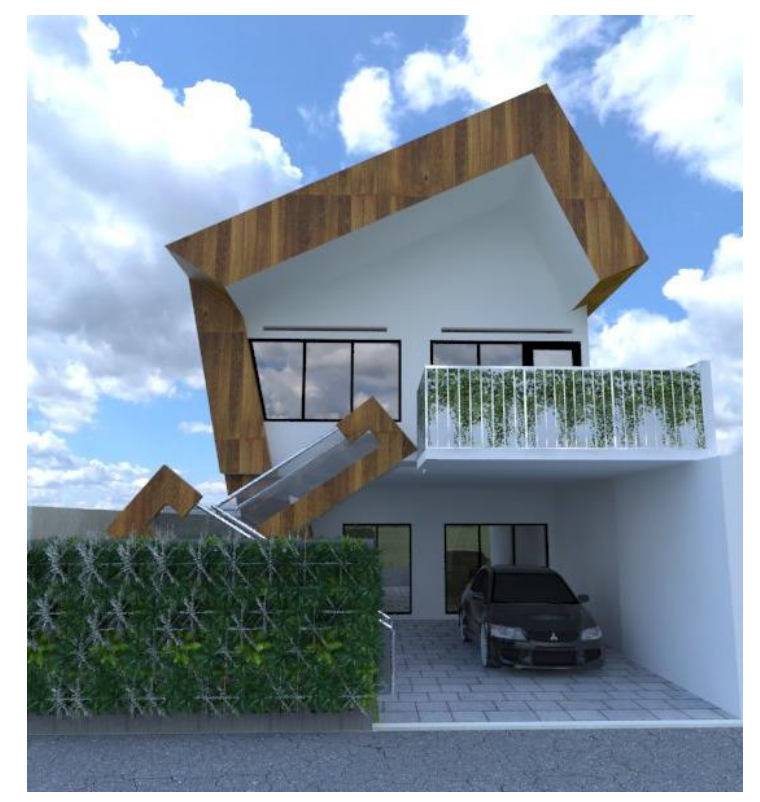

Gambar 15. Tampak Depan

(Sumber: Penulis, 2016)

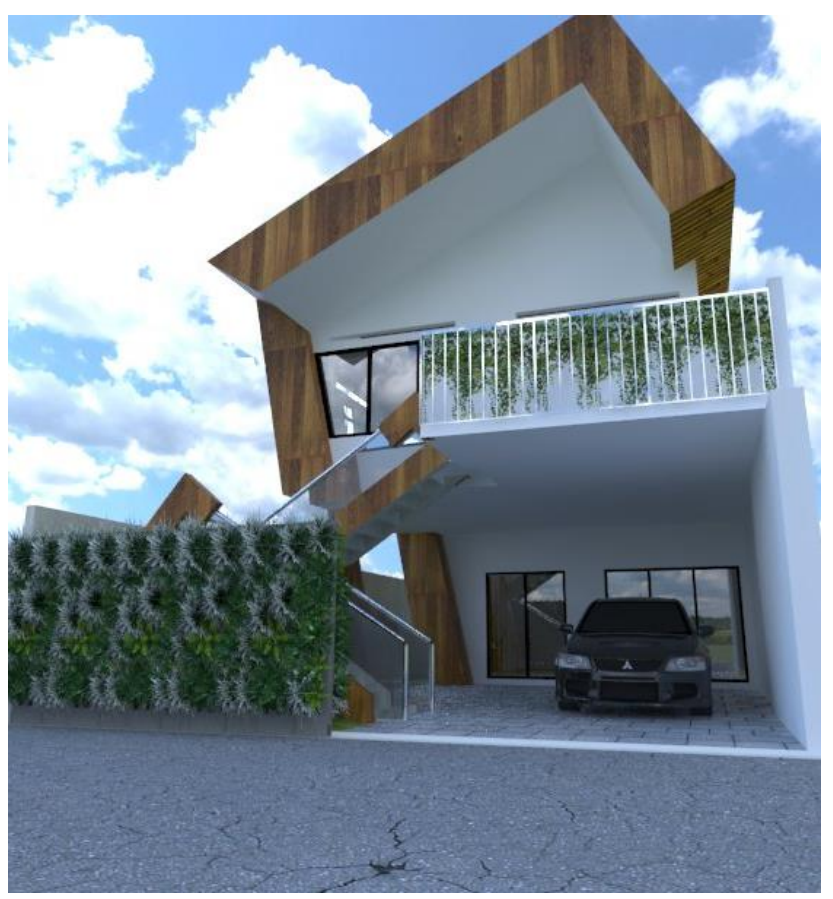

Gambar 16. Tampak Depan 2

(Sumber: Penulis, 2016)
Suasana carport seperti terlihat dalam Gambar 17 berikut:

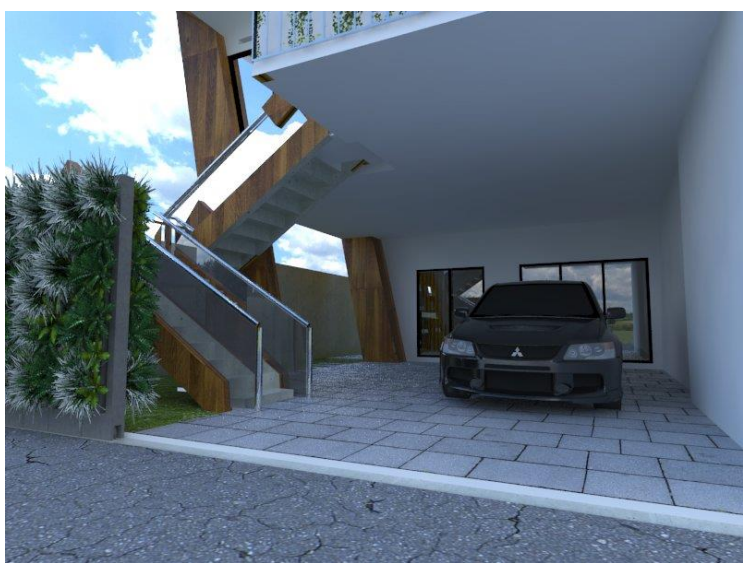

Gambar 17. Carport

(Sumber: Penulis, 2016)

Transformasi bentuk tapis pucuk rebung dan pengaplikasian material bambu terapat pada sisi bagian kiri rumah seperti terlihat pada Gambar 18.

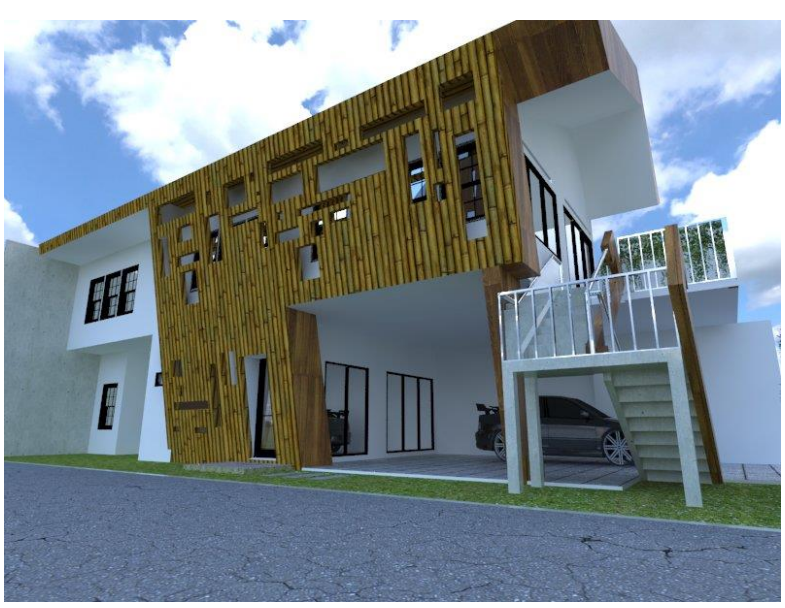

Gambar 18. Tampak Samping Kiri

(Sumber: Penulis, 2016)

Tangga dan railling tranformasi bentuk ukiran kapal seperti terlihat pada Gambar 19. 


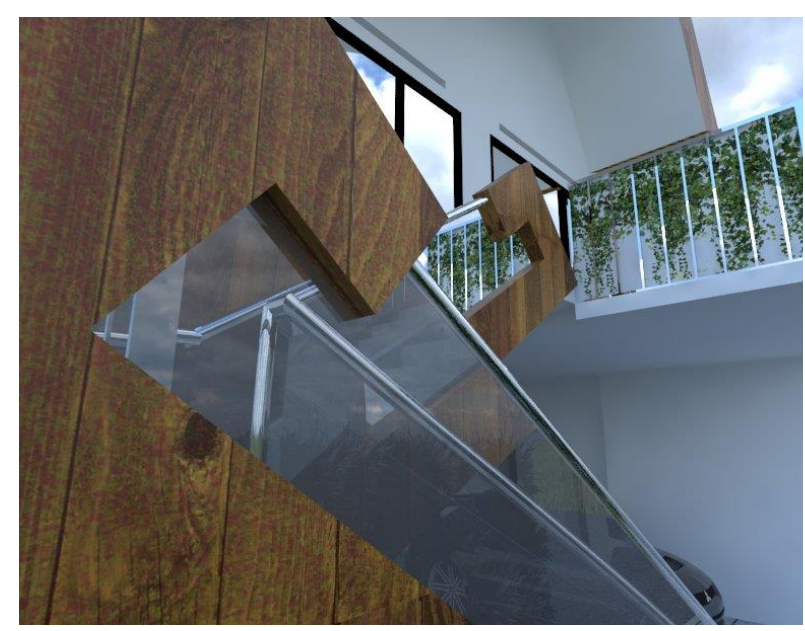

Gambar 19. Detail Tangga (Sumber: Penulis, 2016)

Ruang terbuka di bagian kiri rumah digunakan sebagai sirkulasi dari depan ke bagian belakang banguan dan sebagai sumber pencahayaan dan pengudaraan alami seperti terlihat pada Gambar 20.

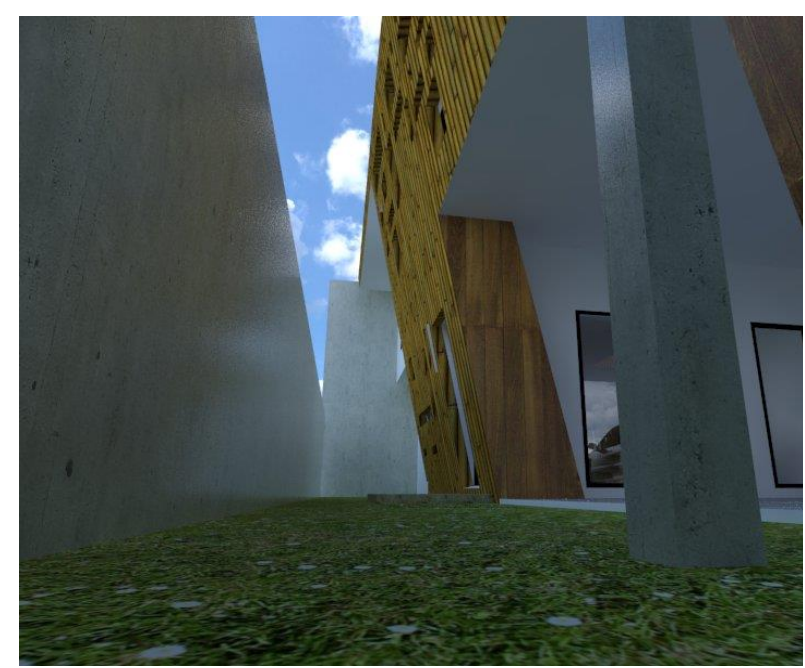

Gambar 20. Samping Lorong Kiri

(Sumber: Penulis, 2016)

Partisi sebagai pengaplikasian flexible room menggunakan roda pada bagian bawah. Desain partisi dan ukuran seperti terlihat pada Gambar 21 dan Gambar 22.

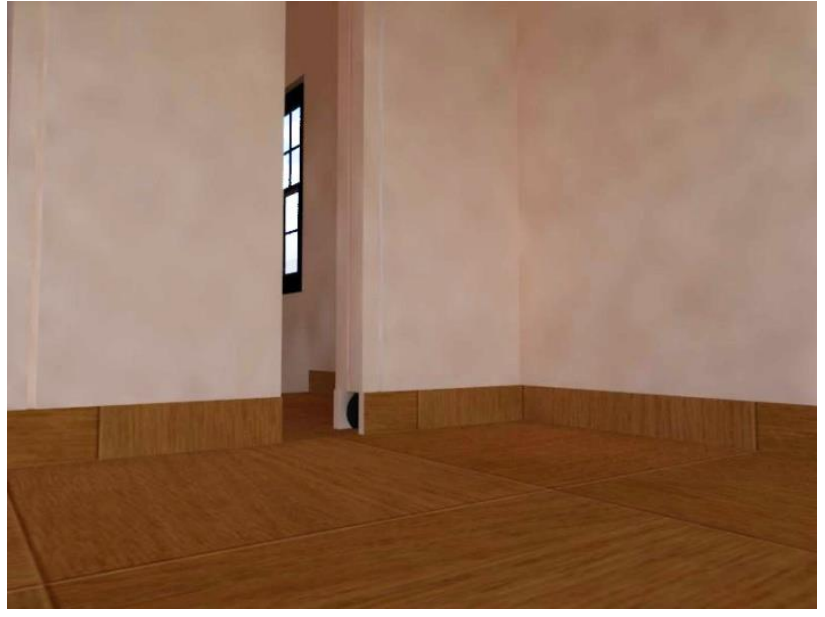

Gambar 21. Detail Partisi 1 (Sumber: Penulis, 2016)

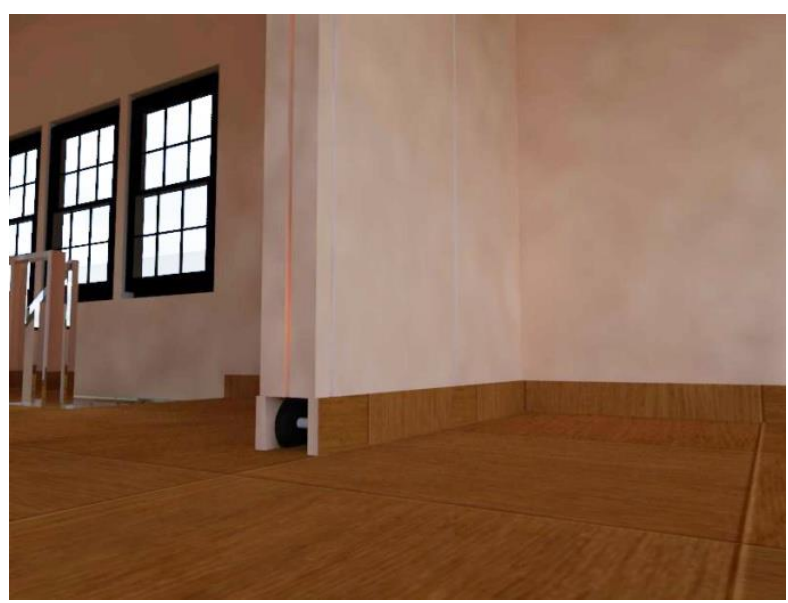

Gambar 22. Detail Partisi 2

(Sumber: Penulis, 2016)

Sambungan partisi memakai baja ringan yang diknock down ke kolom beton. Hal ini dilakukan agar partisi dapat berdiri kokoh meskipun menggunakan roda (lihat Gambar 23).

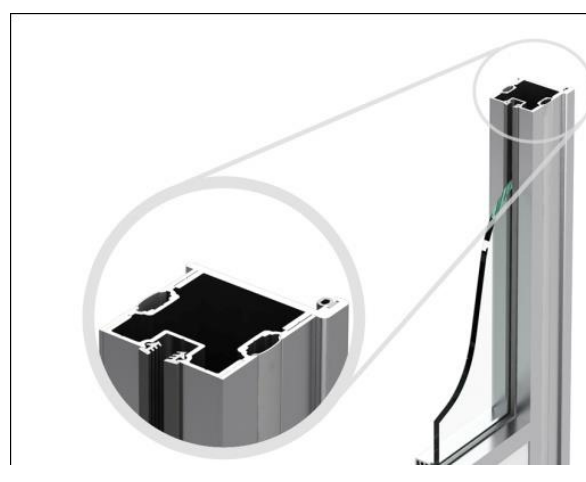

Gambar 23. Detail Sabungan Partisi (Sumber: Penulis, 2016) 
Modul partisi yaitu lebar 80 sentimeter dan tinggi 320 sentimeter seperti terlihat dalam Gambar 24. Penggunaan modul seperti ini disesuaikan dengan ukuran pintu standar. Kemudahan dalam menentukan bukaan (pintu) menjadi dasar penentuan ukuran modul ini.

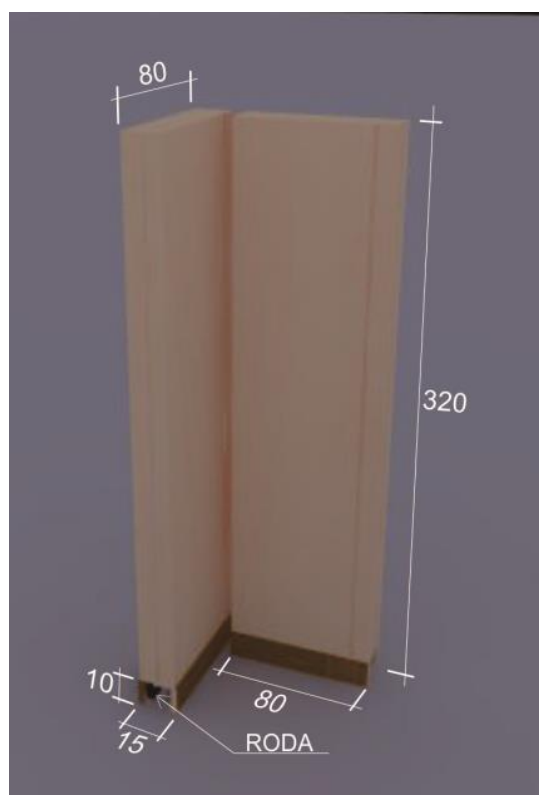

Gambar 24. Modul Partisi

Sumber: Penulis, 2016

\section{KESIMPULAN}

Berdasarkan hasil penelitian dapat disimpulkan bahwa desain rumah typical yang disesuaikan dengan kebutuhan masing-masing penghuni dapat dilakukan dengan menerapakan konsep flexible house. Rumah dapat diciptakan lebih ramah lingkungan dengan menerapakan konsep green architecture sehingga tidak menimbulkan dampak negatif pada lingakungan. Arsitektur Lampung juga dapat diterapkan pada rumah typical dengan cara transformasi bentuk hasil kebudayaan Lampung.

\section{UCAPAN TERIMAKASIH}

Penulis mengucapkan terimakasih kepada Universitas Bandar Lampung yang telah memberikan dana, sarana dan prasarana dalam penelitian ini.

Penulis juga mengucapkan terimakasih kepada Redaksi Jurnal NALARs Universitas Muhamadiyah Jakarta yang telah membantu mempublikasikan penelitian ini. 


\section{DAFTAR PUSTAKA}

[1] Sutalaksana, Tito. (2000). Aspek Pembiayaan Perumahan Khususnya RS dan RSS. Usahawan. No.03 Tahun XXIX, Maret 2000 Hal.8. Jakarta: Erlangga.

[2] Lampung.tribunews.com. (2016). melalui http://lampung.tribunnews.com/2015/05/02/uki ran-khas-lampung-yang-mendunia-dandikagumi-negara-lain [diakses Februari 2016 pukul 21.00]

[3] Malahayati.ac.id. (2016). melalui http://malahayati.ac.id/?p=16745 $\quad$ [diakses Februari 2016 pukul 22.00]

[4] www.harianlampung.co.id. (2016) melalui [http://www.harianlampung.co.id/read/rumahadat-lampung-13/] [diakses Februari 2016 pukul 20.00]

[5] Jeremy Till and Tatjana Schneider. (2015). Flexible housing: the means to the end. Architectural Research Quarterly, 9 (3-4), pp. 287-296, September 2005. Cambridge University Press.

[6] Munawaroh, Ai Siti. (2013). Penerapan Konsep Green Building Pada Existing Building. Tesis pada Program Magister IImu Lingkungan Universitas Padjadjaran Bandung: tidak diterbitkan.

[7] Adhiapradana. (2005). Kantor sewa di Soekarno-Hatta, Bandung ; tema arsitektur hijau. Bandung: TA Arsitektur ITB. Tidak diterbitkan.

[8] Karyono, T. (2010). Green Architecture: Pengantar Pemahaman Arsitektur Hijau Indonesia. Jakarta: Rajawali Press.

[9] ASHRAE. (2006). Green Guide: The Design, Construction, an Operation of Sustainable Buildings. USA: American Society of Heating, RefrigePenilaian and AirConditioning Engineers, Inc.

[10] Steele, J. (1997). Sustainable Architecture: Principle, Paradigms and Case Studies. USA: Mcgraw-Hill Companies.

[11] Hui, S. (1996). Sustainable Architecture. Hongkong: Hongkong University. 